\title{
Resignação de Jó em "Ritual de Danação”, de Gilvan Lemos
}

\author{
Eli Brandão
}

FERRAZ, S., et al.,orgs. Deuses em poéticas: estudos de literatura e teologia [online]. Belém: UEPA; Campina Grande: EDUEPB, 2008. 364 p. ISBN 978-85-7879-010-3. Available from SciELO Books $<\underline{\text { http://books.scielo.org }>\text {. }}$

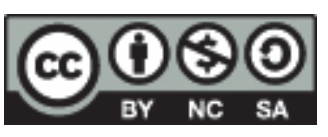

All the contents of this work, except where otherwise noted, is licensed under a Creative Commons Attribution-Non Commercial-ShareAlike 3.0 Unported.

Todo o conteúdo deste trabalho, exceto quando houver ressalva, é publicado sob a licença Creative Commons Atribuição Uso Não Comercial - Partilha nos Mesmos Termos 3.0 Não adaptada.

Todo el contenido de esta obra, excepto donde se indique lo contrario, está bajo licencia de la licencia Creative Commons Reconocimento-NoComercial-CompartirIgual 3.0 Unported. 


\title{
Resignação de Jó em "Ritu- al de Danação", de Gilvan Lemos
}

\author{
Eli Brandão
}




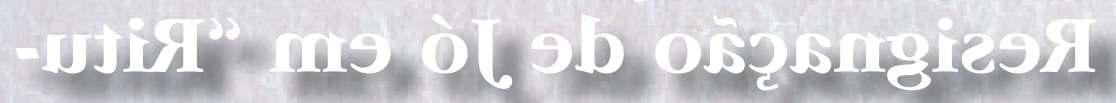

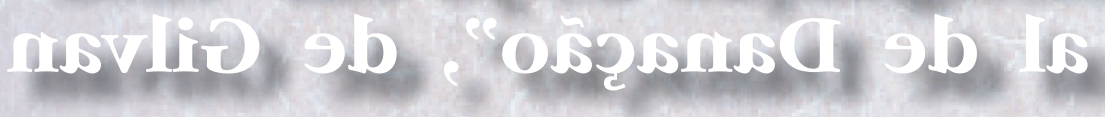
zomist

obobono ra jla 
SILVA, Eli Brandão da*

Resumo: Desde os mais remotos tempos, os deuses dialogam no interior dos textos, e tal é essa relação que, em suas origens, o que hoje chamamos literatura chega a se confundir com o que primeiramente se chamou e ainda se pode chamar de teologia. Ao longo da história da literatura encontramos abundante presença de "textos sagrados" no seio de textos literários, num diálogo intertextual e/ou interdiscursivo incessante, num processo que configura relações de concordância ou discordância, configurando, muitas vezes, intrigantes heterodoxias. Apoiados nas contribuições de Backtin, Maingueneau e Genette, buscamos identificar possíveis relações entre a Novela Ritual de Danação, em A Era dos Besouros, de Gilvan Lemos e o Livro de Jó, da Bíblia, buscando compreender os sentidos teológicos da resignação na novela do pernambucano, suas identidades e suas diferenças em relação ao texto bíblico e às interpretações teológicas deste pelas tradições cristãs.

Palavras-chave: Literatura, Teologia, Resignação, Interdiscurso, Hipertexto.

Summary: From the dawn of time, gods have spoken in texts. And this relation is such that the separate fields which we presently understand as literature and theology were once much less distinct. Throughout the history of literature, "sacred texts" have proliferated at the very heart of literary works. In what can be described as an inter-textual or inter-discursive dialogue, an abundance of concordances and discordances have configured often intriguing heterodoxies. Based on the contributions of Backtin, Maingueneau and Genette, this paper identifies possible relations between Ritual de Danação, a novel of $A$ Era dos Besouros, by Gilvan Lemos, and the Book of Job. These relations are used to clarify the theological meaning of resignation within the novel and clarify its encounters and divergences with the biblical text itself and with its Christian theological interpretations.

Keywords: Literature, Theology, Resignation, Inter-discourse, Hypertext.

* Eli Brandão é Graduado em Letras e Teologia, Mestre em Teologia, Doutor em Ciências da Religião (UMESP-SP). Professor Titular do Departamento de Letras da UEPB, atuando na graduação e pós-graduação na linha de pesquisa "Estudos Socioculturais pela Literatura". Atualmente desenvolve e orienta pesquisas relativas ao sagrado na literatura nordestina. 
Para nos adentramos ao texto de Gilvan Lemos, na trilha labiríntica de seu palimpsesto, partimos da compreensão bakhtiniana de que o discurso não se constrói sobre o mesmo, mas se elabora tendo em vista o outro. Neste sentido, o texto literário é entendido como ponto de intersecção de muitos diálogos. A partir disto, entendemos que, por sua múltipla e complexa configuração, a literatura engendra em seu interior mundos textuais. Isto por um lado estabelece relações com o mundo real, o mundo vivido e, por outro, promove um cruzamento de vozes oriundas de práticas de linguagem socialmente diversificadas que polemizam entre si. Este fato produz incessante convocação e incorporação de contributos textuais e discursivos autônomos e de proveniência diversa (sociais, políticos, religiosos, teológicos, entre outros) presentes na cultura. Tal noção traz implícito o importante conceito de pluridiscursividade e esta como definidora da dinâmica concepção de texto literário.

Reconhecidamente, as contribuições de Bakhtin representaram uma mudança de paradigmas nos estudos lingüísticos, tendo se constituído fundamento das noções mais fecundas da teoria literária contemporânea, dentre as quais destacam-se a de intertextualidade/interdiscursividade e hipertextualidade.

\section{Caminhos-Tecidos}

O termo intertextualidade, processado no ambiente do estruturalismo francês na década de 60 , a partir da reflexão empreendida por Kristeva sobre a obra de Bakhtin, e que pode ser resumido na afirmação de que "Todo texto constrói-se como um mosaico de citações, todo texto é absorção e transformação de um outro texto" (apud. REIS, 1995, p.184), na seqüência da divulgação dos trabalhos do teórico russo, tem sido objeto de aprofundamento e sistematização. A crítica literária atual, ao fazer referência à obra de Kristeva, tem apontado aspectos reducionistas de sua concepção: "à rica e multifacetada concepção do dialogismo em Bakhtin se opôs o conceito redutor, pobre e, ao mesmo tempo, vago e impreciso de intertextualidade." (FIORIN, 1993 p. 30). Em Genette, pelo fato de ter desenvolvido classificação dos diferentes tipos de relações ${ }^{60}$ que o texto pode estabelecer com o outro, o termo é entendido num sentido restritivo, isto é, a presença literal de um texto noutro. A citação, ou seja, a convocação explícita de um texto, ao 60 Referimo-nos a sua teoria da Transtextualidade, na qual distingue cinco tipos de transcendência textual: Arquitextualidade, paratextualidade, intertextualidade, metatextualidade, hipertextualidade. 
mesmo tempo apresentado e distanciado por aspas, é o exemplo mais evidente desse tipo de função, que comporta também a estlilização e a alusão. Sobre o mesmo conceito, autores como Riffaterre se distinguem da noção clássica, pois consideram o traço intertextual muito mais alusivo (RIFFATERRE, 1989, p. 41). Ponto de vista semelhante pode ser visto em Laurent, para quem "basta uma alusão para introduzir no texto centralizador um sentido, uma representação, uma história, um conjunto ideológico (...). O texto originário lá está, virtualmente presente, portador de todo o seu sentido sem que seja necessário enunciálo."(LAURENT, 1988, p.14). Percebe-se, a partir disso, a diversidade de conceitos e a própria limitação do mesmo. Eis o porquê da necessidade de, para dar mais profundidade à análise, a ele associarmos outros dois, o de interdiscursividade e o de hipertextualidade.

Destaquemos aqui, uma significativa distinção entre intertextualidade e interdiscursividade. Havendo intertextualidade haverá interdiscursividade, visto que o enunciador, necessariamente, se refere ao discurso que o texto manifesta. $O$ inverso, porém, não se configura como verdade, pois pode haver interdiscursividade sem haver intertextualidade (FIORIN, 1994, p. 30-35). O processo interdiscursivo ocorre quando se incorporam temas e/ou figuras, percursos temáticos e/ou figurativos de um discurso em outro. E todo discurso define sua identidade em relação ao outro, constituindo, por isso, uma heterogeneidade constitutiva que revela, por um lado, sua identidade e, por outro, sua diferença, como observa Maingueneau (1993, p. 116). De modo que o interdiscurso deve ser entendido como um processo de reconfiguração incessante no qual uma formação discursiva é levada a incorporar elementos pré-construídos, produzidos fora dela, com eles provocando sua redefinição e redirecionamento, suscitando, igualmente, o chamamento de seus próprios elementos para organizar sua repetição, mas também provocando, eventualmente, o apagamento, o esquecimento ou mesmo a denegação de determinados elementos (MAINGUENEAU, 1993, p.113). Neste sentido, toda formulação discursiva se situa na intersecção de dois eixos: o vertical, do pré-construido, domínio da memória discursiva; e o horizontal, da linearidade do discurso, que oculta o primeiro eixo. (Id. p.115-116). O interdiscurso pode ser mais bem entendido através da distinção, feita por Maingueneau, entre as noções de Universo discursivo; campo discursivo; e espaços discursivos. O primeiro é constituído pelo "conjunto de formações discursivas de todos os tipos que interagem numa dada conjuntura” (Id. p.115), não podendo ser, por causa de sua amplitude, apreendido em sua glo- 
balidade; o segundo refere-se ao conjunto de formações discursivas que se encontram em concorrência e se delimitam reciprocamente em uma região determinada do universo discursivo (Id. p.116), podendo ser exemplificado pelo campo político, filosófico, teológico, gramatical, etc.; o terceiro, os espaços discursivos, delimitam subconjuntos ou recortes que o analista isola no interior de um campo discursivo tendo em vista os propósitos específicos de sua análise.

A constatação de Perrone-Moisés, após demonstrar um processo histórico de reescrituras, é elucidativa: "a literatura sempre nasceu da literatura" (1995, p.27). Mais do que palimpsesto, a obra literária, às vezes, como observa Schneider, nos dá uma certa vertigem, pois através da inscrição do texto vislumbramos "palimpsesto de palimpsestos" (1990, p.75).

Genette desenvolve, em Palimpsestes. La littérature au second degré, o conceito Palimpsesto, aplicando-o à obra literária. Um palimpsesto, afirma ele, é literalmente um pergaminho do qual uma inscrição anterior foi apagada para que uma outra a substituísse. Tal operação, entretanto, não conseguiu apagar irremediavelmente o texto anterior. De modo que o mais antigo pode ainda ser lido no atual como por transparência. Um texto, então, como diz Genette, sempre pode camuflar um outro, mas nunca consegue dissimulá-lo completamente (1982, p.12). Nesta relação, um texto se apresenta e apresenta o outro: mas interpreta melhor quem interpreta o último. $\mathrm{O}$ autor antigo escreveu uma primeira vez, depois sua escritura foi apagada por algum copista, que recobriu a página com um novo texto e assim por diante. Entretanto, por mais que se tente, o apagar nunca é tão apagado que não deixe vestígios, a invenção nunca é tão nova que não se apóie sobre o já escrito (SCHNEIDER , 1990, p.71).

Para Genette, o palimpsesto, por excelência, é o hipertexto. A hipertextualidade é por ele definida como toda relação que une um texto $\mathrm{B}$ (Hipertexto) e um texto A (Hipotexto), à semelhança do que ocorre com a metáfora, e pode ser resumida em dois processos: transformação e imitação, embora esta última seja também uma forma complexa de transformação (1982, p. 14). O hipertexto passa, portanto, por processos de transformação que se apresentam como ampliação, redução ou substituição, do texto com o qual se relaciona, sendo o mesmo, geralmente, uma obra literária. É, neste sentido, a transformação deliberada de um texto primeiro ou vários por um segundo, sendo o hipertexto uma classe de textos que engloba inteiramente certos gêneros 
canônicos como o pastiche (MAINGUENEAU, 1993, p.113) ${ }^{61}$, a paródia (SANT'ANNA. 1998, p. 12) ${ }^{62}$, entre outros.

Genette procura mostrar que, como todas as categorias genéricas, a hipertextualidade se declara melhor por meio de uma indicação paratextual de valor contratual: Virgílio Travesti, por exemplo, é um contrato explícito de imitação burlesca; Ulisses é um contrato implícito e alusivo o qual deve, ao menos, alertar o leitor sobre a existência provável de uma relação entre esse romance e a Odisséia, etc. Nisto percebe-se que algumas obras se apresentam mais explicitamente hipertextuais do que outras. Virgile Travesti mais do que as Confissóes de Rosseau, por exemplo. Por isto, Genette ressalta que, quanto menos compacta e evidente se apresentar a hipertextualidade de uma obra, mais a sua análise depende de um julgamento constituído, determinado por uma decisão interpretativa do leitor. Ele afirma, o intérprete pode até decidir que as Confissões de Rosseau é uma recomposição atualizada das Confissões de Santo Agostinbo, e que o seu título é a sua relação contratual, mas ele precisaria confirmar tal engenhosidade crítica através da análise dos detalhes. Para Genette, tal atitude apresentaria uma limitação, pois a valorização das descobertas parciais e das indicações localizadas e fugidias levaria o estudo para fora do âmbito da hipertextualidade. Esse estudo se tornaria de pouco domínio, já que, sobretudo, daria um crédito e uma concordância, um script (roteiro), na opinião de Genette, pouco sustentável, à atividade hermenêutica do leitor - ou do arquileitor. Genette deixa claro que, de modo algum, concordaria com uma espécie de hermenêutica hipertextual, pois considera a relação entre o texto e o seu leitor de uma maneira mais socializada, mais claramente contratual, como observância de uma práxis consciente e organizada (1982, p.18-19).

Pela complexidade do texto literário e pelas limitações de uma análise meramente intertextual ou hipertextual, nossa abordagem neste artigo é mais próxima do que chamamos de hermenêutica transtex61 O Pastiche distingue-se, em princípio, da paródia dado que o pastiche ideal é falso; ele deveria poder figuram entre obras do corpus que imita. $\mathrm{O}$ autor do pastiche utiliza indícios de distanciamento (aumento de efeitos, por exemplo). O fato de produzir novas obras do mesmo tipo a partir do conhecimento de algumas, supõe uma certa competência. A interiorização de regras que governam o gênero.

62 Tomando por base o Dictionary of World Literature de Shipley, Romano de Sant'Anna que o termo grego paródia implicava a idéia de uma canção cantada como um contracanto. Uma espécie de ode que pervertia o sentido de outra, numa imitação burlesca. Ressalta que modernamente a paródia se define muito mais através de um jogo intertextual. 
to-discursiva (SILVA, 2007). Isto porque trata-se de uma hermenêutica com degrau analítico, que conjuga a abordagem hipertextual de Genette a elementos de semântica discursiva. Consideramos a existência de um texto que se constitui ocultando e revelando um outro, mas não por uma operação de mera repetição e sim por um processo criativo e dialogicamente crítico. Não será, portanto, uma leitura rigorosamente hipertextual, como sugerida em Palimpsestes, porque possui, além do degrau textual propriamente dito, um degrau semântico-discursivo e outro hermenêutico. A partir disso, a denominação desta leitura inspira-se num termo subvalorizado por Genette (1982, p.18-19), ao se referir à atividade hermenêutica na identificação dos processos hipertextuais, em contraposição à sua prática mais contratual e mais explícita. Entendemos, entretanto, que está pressuposto na identificação de uma relação hipertextual uma hermenêutica. Associar dois ou mais textos implica uma compreensão, pois o leitor apenas reconhece uma relação contratual, por causa de pré-conhecimento dos textos envolvidos e por causa de uma determinada interpretação do fato, porque o intérprete jamais se aproxima do que diz o seu texto se não viver na aura do sentido interrogado (Ricoeur, 2000, p. 251)

Por não haver temas especificamente literários e pela potência palimpsêstica e pluridiscursiva da literatura, "a obra pode ser concebida e julgada do ponto de vista de qualquer dos valores nela contidos" (MUKARÓVSKY, 1981, p.128, 169, 170). Ora, ao longo da história da literatura encontramos abundante presença de "textos sagrados" no seio de textos literários, num diálogo intertextual e interdiscursivo incessante, num processo que configura relações de concordância ou discordância com os textos/discursos das religiões. É inquestionável a influência exercida pela Bíblia na formação do imaginário e dos valores das sociedades no contexto sociocultural do Ocidente. De modo que qualquer compreensão relativa ao humano que vive neste contexto será devedora à compreensão do tipo de relação que este estabeleceu com a herança judaico-cristã.

Nesta via, tentaremos neste artigo identificar e interpretar possíveis relações entre a Novela Ritual de Danação, do livro A era dos besouros, de Gilvan Lemos, e o Livro de Jó, da Bíblia, buscando compreender os sentidos teológicos da resignação na reescritura do autor pernambucano, suas identidades e suas diferenças em relação ao texto bíblico e às interpretações teológicas das tradições judaico-cristãs.

Este artigo inscreve-se no contexto dos atuais debates em torno 
das relações entre Literatura e Teologia. Relações estas que revelam que, desde os mais remotos tempos, perpassando narrativas míticas, textos fundantes das grandes religiões, ditirambos no teatro grego antigo, da antiguidade até os nossos dias, textos e discursos sobre os deuses em diálogo no interior de textos literários ou teológicos, numa prosa quase sempre poética (SILVA, 2005). E tal é essa relação que, em suas origens, o que hoje chamamos literatura chega a se confundir com o que primeiramente se chamou e ainda se pode chamar de teologia.

\section{Ritual de danação como palimpsesto}

A novela Ritual de Danação, de Gilvan Lemos, narra a estória de Simão Pedro, homem pobre e católico muito devoto, que morava num sótão de um sobradinho (dois cômodos) com sua mulher, Laura e seus filhos, Maria, Geraldo, Jonas e Letinha. Trata-se de um drama urbano contemporâneo, ocorrido num bairro do Centro antigo da cidade do Recife.

Como toda leitura engendra uma reescritura (Ricoeur, 1995), a prévia leitura do texto de Lemos nos sugere uma conjectura palimpsêstica entre a estória de Simão Pedro e a estória de Jó da Bíblia. E como, num certo sentido, o texto é mudo (Id. p.120), o leitor passa a ser necessariamente o seu intérprete. A tarefa, entretanto, não é completamente arbitrária, porque o texto ocupa um lugar semelhante ao de uma partitura musical e o leitor, analogamente, ao de um maestro que segue as instruções da notação. A compreensão do texto, neste caso, não se confunde com a repetição do evento do discurso num evento semelhante, pois, embora ela tenha início com o texto em que o evento inicial se objetou, apresenta-se como geradora de um novo acontecimento $^{63}$. Pressupomos que a obra do pernambucano reescreve o percurso temático presente no Livro de Jó e que a figura deste está transmudada na figura de Simão Pedro. As marcas do hipotexto bíblico estão dissimuladas no Ritual de danação.

Sigamos o curso da narrativa, atentando para os possíveis diálogos com o texto bíblico. Afirmamos que Simão Pedro era pobre. Mas o narrador onisciente diz mais ainda.

Depois, era pobre, bem dizer miserável, no entanto reconhecia: gramara dias piores. Com menos de vinte anos perdera os pais. Ainda sem muita

63 Paul Ricoeur. Teoria da Interpretação. p.121. 
experiência consertava sapatos, comia na hora os vinténs ganhos parcamente, quando os ganhava. Possuía a roupa do corpo, não tinha onde cair morto. Hoje, não se gabava, mas tinha mulher e filhos, um teto, três refeições diárias. A vida era assim mesmo. [...] Futuramente, a Deus querer, os filhos se situariam em melhores condições, estava visto. (LEMOS, 2006, p.12)

Simão Pedro, diferente de Jó, que era rico, era pobre. Mas, por outro lado, em relação ao discurso sobre as posses, vê-se entre eles uma identidade nesta diferença. Se Jó era cúmulo de bens, Simão era cúmulo de falta de bens. Outra identidade entre eles é que Simão Pedro era, como Jó, homem temente a Deus e Nele depositava a esperança de dias melhores. E o sinal estava dado: se não era rico, pelo menos era menos pobre do que já fora.

Também, antecipadamente, tinha a consciência de que nunca sentiria a perda dos bens materiais como no caso de Jó, pois nunca os tivera e, desse modo, não podia sentir a perda do que nunca desfrutara:

Era aí que Simão Pedro queria chegar. Não dera conforto a Laura? Nenhum dos dois, antes, conhecera conforto, de modo que ele ou Laura não podiam estranhar desconforto. Taí. A vida é assim mesmo, achava Simão. A pessoa desfruta do seu momento, só se sente falta do que teve e não tem mais. Se nunca teve... (LEMOS, 2006, p.19)

O dono da bodega, Marajó, topônimo que parecia uma espécie de aglutinação de disfarce de Jó, um Jó amargo, Jó às avessas. Suas ações ora nos remetem para a figura do diabo, que busca afastar Simão Pedro da fé em Deus, ora nos remetem às figuras dos amigos de Jó, que querem convencê-lo de que é culpado pela vida miserável que leva.

Somos uns lascados. Sabe por quê? Porque vivemos honestamente, cumprindo com nossas obrigações. [...] Você, com esse fanatismo, batendo nos peitos, saindo em cordão de irmandade, besteira, homem. Se iluda não. Deus não gosta de gente pobre, se gostasse ajudava a gente, mas o que faz? Castiga o mais que pode. Quem se pega com Deus não sai da merda. (LEMOS, 2006, p.12, negrito nosso) 
Marajó não cessava de tentar mostrar a Simão Pedro a infidelidade e até sacanagem de Deus. "O pobre nunca deve dizer que está feliz ou infeliz. Se disser que tá feliz tá é mentindo. E se disser que tá infeliz, Deus acha pouco e manda mais infelicidade pra cima dele." (Id. p.26)

E quando as coisas começaram desmoronar na vida de Simão Pedro, não eram de conforto as palavras de Marajó: "E tem uma coisa, Simão, prepare-se para novas rebordosas, uma desgraça nunca vem sozinha, vem sempre acompanhada." (Id. p. 30)

A tempestade natural, para Marajó, era uma metáfora das desgraças humanas. "- é o dilúvio, não tem o que discutir. Gentilezas do seu bom Deus, Simão. O gozo Dele é ver muito mocambo caído, muito pobre desabrigado. É ou não é?” (Id. p. 31)

Mas para Simão Pedro, sua resignação tinha em vista a soberania de Deus. "Tudo se encaminhava ao destinado ponto designado por Deus." (Id. p.20). Em diálogo com sua mulher, Laura, ele reforçava sua posição passiva.

- O que tiver de acontecer acontece.

- E fica por isso mesmo?

- Ninguém prevê a vontade de Deus, minha velha.

- Não, ninguém. E a vontade Dele nunca é boa pra gente. (LEMOS, 2006, p. 23)

E assim justificava sua devoção a Deus e o seu compromisso com os deveres da igreja: "É por todos nos que rezo, peço os favores de Deus, se Ele quiser nos favorecer. Se não quiser, paciência. A vontade Dele é que prevalece." (Id. p.24)

Quando Laura descobriu que estava com câncer e teve que se internar para fazer uma cirurgia, ele a consolava reafirmando sua confiança em Deus. "Volta, com a graça de Deus você volta. Só fica lá uns dias, até cicatrizar. A Deus querer, e Ele há de querer, num instante cicatriza." (Id. p.33)

Num contexto em vivia sujeito a toda sorte de privações, para a fome que enfrentava com sua filha de doze anos, numa fala em tom quase profético, ele articula um discurso no qual funde Deus e o Governo como seu consolo: “- Graças a Deus o governo nos dá essa ajuda." (Id. p.35)

Simão Pedro, que já nada de material possuía, tinha na mulher e nos filhos sua riqueza. Mas não tardou e, como pedra redonda de ladei- 
ra a baixo, numa seqüência gradativa, como também ocorreu no caso de Jó, os males foram se manifestando implacavelmente. Maria, sua filha, fugiu para o Rio de Janeiro com estranhos, depois do carnaval, e dela ninguém mais soube notícia; Geraldo morreu num acidente de carro quando retornava da Nova Jerusalém, onde fora assistir ao drama da Paixão de Cristo; seu filho Jonas envolveu-se com traficantes de drogas e foi morto como queima de arquivo; sua mulher, Laura, morreu de câncer, depois de muito sofrimento; e sua caçula, Letinha, foi encontrada morta debaixo do viaduto, depois de ser estuprada.

Depois da ocorrência de todas estas desgraças, Simão Pedro desaparece de cena. O seu nome é simbólico. Nada tem de parecido com o seu homônimo bíblico, que era apóstolo e conhecido como intrépido e corajoso. Simão era covarde, faltava-se força para enfrentar a vida. Era por demais resignado. Sua resignação ligava-se à sua religião. $\mathrm{O}$ seu silêncio aqui é análogo ao silêncio de Jó. Quando reaparece, já não é mais o mesmo. Seu desespero está a um fio do trágico, pois seu espírito está atormentado. Andando sozinho e sem rumo pelas ruas da noite escura do Recife defronta-se mais uma vez com sua ruína existencial, quando passa por perto do sótão onde morara com sua família agora extinta.

[...] avistara a janela do Sótão, ali permanecia estático, perplexo, fascinado, sem força de desviar a vista, na garganta um sufoco de angústia, no peito, estreitando-o, um laço de arame farpado, naquela dor profunda que o arrastava pra dentro dum buraco escuro e sem fim. Como pudera aquilo acontecer sucessivamente? Era possível? Afinal, estava ali sozinho, sem ninguém? Ninguém?

Como num vômito intenso e inesperado, o silêncio da noite é quebrado por um grito revelador, numa referência análoga e explícita ao do seu palimpsesto bíblico:

- Mas meu Deus, eu não sou Jó! (LEMOS, 2006, p. 42 , negrito nosso)

Seu grito nos remete interdiscursivamente ao Jó da Bíblia, que também, em profundo desespero, depois de perder seus bens, sua saúde e sua família, gritara:

Pereça o dia em que nasci, a noite em que se disse: um menino foi concebido! Esse dia, que se torne trevas, que Deus do alto não se ocupe dele, que 
sobre ele não brilhe a luz! [...] Porque Deus não fechou a porta do ventre para esconder à minha vista tanta miséria. Porque eu não morri ao deixar o ventre materno ou pereci ao sair das entranhas? (Jó, 3,3-4,10)

O grito de Simão Pedro calou. Ele sai dali e encontra no caminho um palanque armado. Era um comício. Ali, muitos políticos discursavam, fazendo todo tipo de promessa, enquanto aguardavam o orador principal, o candidato a governador do Estado.

Simão Pedro pára ao pé da escada que dava acesso ao palanque. O narrador silencia. Não nos diz ele, em sua onisciência, o que passava na mente de Simão. Quando nos apresenta os fatos, lá vem, rompendo a turba, a comitiva oficial. À frente, o candidato a governador, gesticulando, jogando beijos com as mãos, protegido pelos seus seguranças. À entrada do palanque, um tumulto inesperado gerou correria, confusão, gritos, seguidos de disparos e mais gritos. Som da sirene da ambulância, multidão dispersa, silêncio...

Ficamos sabendo depois que a resignação de Simão Pedro, em sua plenitude, se transmudara em revolta e agressividade. Talvez a revolta estivesse voltada para aquela fusão que fizera, quando tentava consolar sua filha faminta. Pode estar implícito o esgotamento de sua resignação religiosa, mas seu grito se traduz em ação contra aquele que passa a ser identificado como o causador de todos os males, o político, o símbolo do governo. Enfia-lhe mortalmente uma faca na barriga. Os seguranças imediatamente, à queima roupa, liquidam Simão Pedro: "Nasceu nu, pobre e sem nada, e nu morre." (Jó, 1,21)

Depois de passadas estas coisas, Marajó, num riso revelador, abre as portas do seu estabelecimento e, voltando-se de súbito para o Gordo (jornaleiro), apontando para o jornal com

[...] um riso diabólico no rosto largo:

- Aí diz que Simão Pedro enlouqueceu? Pois para mim foi justamente quando criou um pouco de juízo. Se eu soubesse que Simão Pedro ia fazer o que fez tinha-lhe comprado uma metralhadora. $\mathrm{O}$ arraso seria completo. Este país ta precisando duma limpa geral, Gordo. Diabos! 


\section{Paciência ou revolta?}

Simão Pedro e Jó fazem o mesmo percurso temático, ressaltadas as identidades e as diferenças próprias da refração literária.

\begin{tabular}{|c|c|c|}
\hline Jó & & Simão Pedro \\
\hline Cúmulo de posses & & Cúmulo de falta de posses \\
\hline Aposta do Diabo & & Aposta do amigo \\
\hline Privação de tudo e miséria geral & & Privação de tudo e miséria geral \\
\hline Acusação dos amigos & $=$ & Acusação do amigo \\
\hline Silêncio e grito de desespero & & Silêncio e grito de desespero \\
\hline $\begin{array}{r}\text { Revolta contra o discurso dos } \\
\text { amigos }\end{array}$ & & $\begin{array}{l}\text { Revolta contra o representante } \\
\text { do governo }\end{array}$ \\
\hline $\begin{array}{r}\text { Como no início, Cúmulo de } \\
\text { posses e de filhos }\end{array}$ & & $\begin{array}{l}\text { Como no início, cúmulo de } \\
\text { miséria }\end{array}$ \\
\hline
\end{tabular}

A resignação de Simão Pedro explodiu em revolta. Se sua resignação era por motivos de fé, qual teologia estaria implícita às suas atitudes passivas? Não seria a resignação do homem rico e justo, que perde tudo, mas tem fé que o Deus justo lhe retribuirá em dobro. Também não seria a resignação de quem se julga pecador e culpado de alguma falta essencial. Seria a resignação apenas por temer a Deus ou por acreditar incondicionalmente na soberania de Deus? Talvez sua resignação estivesse mais próxima daquela dos miseráveis, expressão de um ser apequenado, que já entra em cena derrotado, que é imobilizado desde cedo e não encontra forças para se soltar das amarras, que não consegue sequer ter esperança.

Quando atentamos para o momento em que Simão Pedro diz: "Se não quiser, paciência. A vontade Dele é que prevalece." (LEMOS, 2006, p.24), constatamos que sua resignação aparece relacionada à paciência, encontrando eco em uma interpretação cristã relativa à atitude de Jó em seu sofrimento. Mas se observarmos bem o texto de Jó da Bíblia, constataremos que ele não foi paciente coisa nenhuma. Jó foi sim, diante de Deus e dos seus amigos, um questionador de sua condição. Por um momento parece se resignar, mas em seguida revolta-se e mantém uma atitude contestadora, através da qual reclama da justiça de Deus que, em face de sua inocência, apresenta-se como injustiça. É provável que esta interpretação cristã da atitude de Jó esteja menos referenciada ao texto da Bíblia do que à necessidade de atribuir ao 
patriarca bíblico um fruto do espírito (paciência), conforme relação de frutos do espírito registrada na Carta de Paulo aos Gálatas. Seja como for, percebe-se tanto em Simão quanto em Jó que, em face da injustiça e da dor mais profunda, a resignação encontra o seu limite e se transmuda em revolta.

O preceito teológico que, em comum, permeia a novela Ritual de Danação e o Livro de Jó é o da indagação sobre a causa do sofrimento do justo. Que relação há entre riqueza ou pobreza e justiça? Nas duas obras, Deus fica sob juízo, mas o Jó da Bíblia recebe riqueza ainda maior do que a que possuía e Simão Pedro recebe miséria ainda maior do que a que possuía, perdendo, até sua vida. Mas nesta identidade, uma diferença que toca o limite entre dois gêneros se ressalta: Jó é um épico e Ritual de Danação é um drama trágico.

O palimpsesto está aberto às diversas interpretações. A novela Ritual de Danação dissimula as marcas textuais e discursivas do hipotexto do Livro de Jó, revelando um hipertexto carregado de sentidos, dentre os quais o teológico que já se prenuncia político. 


\section{Referências}

Bíblia de Jerusalém. São Paulo: Paulinas, 1987

FIORIN, José Luiz. Elementos de Análise do Discurso. São Paulo: Contexto, 1994.

GENeTTE, Gérard. Figuras. São Paulo: Perspectiva,1972.

GENETTE, Gérard. Palimpsestes. La littérature au second degré. Paris: Éditions du Seuil, 1982.

JENNY, Laurent. A Estratégia da Forma. In: Poetíque: Intextextualidades. Coimbra: Almedina. 1979.

LEMOS, Gilvan. A Era dos besouros. São Paulo: Girafa, 2006

MAINGUENEAU, Dominique. Novas Tendências em Análise do Discurso. Campinas: Unicamp, 1993.

MUKARÓVSKY, Jan. Escritos sobre Estética e Semiótica da Arte. Lisboa: Estampa, 1981.

PERRONE-MOISÉS, Leyla. Altas Literaturas. São Paulo: Companhia das Letras, 1998.

REIS, Carlos. O Conhecimento da Literatura. Coimbra: Livraria Almedina, 1995.

RICOEUR, Paul. O Conflito das Interpretações. Rio de Janeiro: Imago, 1978.

RICOEUR, Paul. Teoria da Interpretação. Porto: Porto Editora, 1995.

RIFFATERRE, Michael. A Produção do Texto. São Paulo: Martins Fontes, 1989 .

SAN'ANNA, Romano. Paródia, paráfrase \& Cia. São Paulo: Ática, 1998. 
SCHNEIDER, Michel. Ladrões de Palavras. Campinas: UNICAMP, 1990.

SILVA, Eli Brandão. ... e o divino se faz verbo. In: Estudos de Religião 29. São Bernardo do Campo: UMESP, 2005.

SILVA, Eli Brandão. Jesus-Severino e a teimosa esperança. In: Estudos de Religião 32. São Bernardo do Campo: UMESP, 2007. 